\title{
Prenatal diagnosis in Treacher Collins syndrome using combined linkage analysis and ultrasound imaging
}

\author{
S J Edwards, A Fowlie, M P Cust, D T Y Liu, I D Young, Michael J Dixon
}

\begin{abstract}
Treacher Collins syndrome is an autosomal dominant disorder of facial development, the features of which include conductive hearing loss and cleft palate. In the current investigation, linkage analysis has been used to make first trimester diagnostic predictions in a pregnancy at high risk of producing an affected child. The results of this analysis predicted that the child would be affected. As predictions of the severity of the disease were not possible, the pregnancy was also assessed by ultrasound imaging. This confirmed the affected diagnosis and predicted that the child would be severely affected.

(f Med Genet 1996;33:603-606)
\end{abstract}

Key words: Treacher Collins syndrome; human chromosome 5; prenatal diagnosis.

Treacher Collins syndrome (TCOF1) affects approximately 1 in 50000 live births and is inherited in an autosomal dominant fashion. Forty percent of affected subjects have a previous family history, the remaining $60 \%$ of cases arising as a result of a de novo mutation. The clinical characteristics of the disease include

School of Biological

Sciences and

Departments of Dental

Medicine and Surgery,

3.239, Stopford

Building, University of Manchester,

Manchester M13 9PT

UK

$S$ J Edwards

M J Dixon

Department of

Obstetrics and

Gynaecology, Derby

City General Hospital,

Derby, UK

A Fowlie

M P Cust

Department of

Obstetrics and

Gynaecology,

City Hospital,

Nottingham, UK

D T Y Liu

Department of Clinical Genetics, City Hospital, Nottingham, UK I D Young

Correspondence to: Dr Dixon.

Received 6 December 1995 Revised version accepted

for publication

for publication
(1) hypoplasia of the mandible and zygomatic complex; (2) abnormalities of the pinnae, often associated with atresia of the external auditory canals and anomalies of the middle ear ossicles leading to a conductive hearing loss ${ }^{1}$; (3) downward slanting palpebral fissures with colobomata of the lower eyelids; (4) cleft palate. While the clinical features are generally bilaterally symmetrical, expression of the mutated gene is highly variable. At one extreme the features can be so mild that it may be difficult to reach a diagnosis. ${ }^{2}$ At the other extreme the facial complex may be so severely hypoplastic that perinatal death ensues as a result of compromisation of the airway. Rarely, non-penetrance may occur, ${ }^{2}$ although in the vast majority of cases where this is suspected careful examination of the obligate carrier will show minor stigmata of the disorder. ${ }^{3}$

As part of the continuing attempts to isolate the mutated gene, TCOF1 has been mapped to $5 \mathrm{q} 31.3-32^{4-8}$ and a high resolution genetic map of short tandem repeat polymorphisms (STRPs) encompassing the disease locus has been produced. ${ }^{9}$ All the families that have been analysed to date (approximately 50 ) support linkage of the disease locus to markers in the same region of the genome, with none showing unequivocal evidence of non-linkage. ${ }^{7-10}$ These data support genetic homogeneity.

Postnatal diagnostic predictions have been made in mildly affected, and apparently unaffected, subjects using linked STRPs. ${ }^{2}$ However, prenatal diagnosis has only been performed in families with a history of TCOF1 using either fetoscopy ${ }^{11}$ or ultrasound imaging in the second trimester. ${ }^{1213}$ The procedure related fetal mortality rate for fetoscopy is low (approximately $2 \%$ ) and is acceptable for the majority of patients with a high recurrence risk. ${ }^{14}$ While the quality of ultrasound imaging has improved markedly in recent years, allowing non-invasive prenatal diagnosis to be made, it can still be difficult to make a positive diagnosis where the fetus is mildly affected. Prenatal diagnosis using either fetoscopy or ultrasound imaging is not possible until the second trimester of pregnancy (approximately 18 weeks). At this time termination of pregnancy is a particularly traumatic procedure psychologically as it involves the induction of labour. First trimester prenatal diagnosis would therefore seem to be preferable, particularly if the family feel that termination of pregnancy is desirable in the event that the fetus is affected. Nevertheless, chorionic villus sampling conveys the twin disadvantages of a miscarriage risk and a lack of information about disease severity, which must be discussed with the parents before any invasive testing. Consequently, parents who opt for chorionic villus sampling, and subsequently receive an unfavourable result, may then quite understandably defer their decision pending the outcome of detailed ultrasound scanning. Even then the decision can be an extremely difficult one, as illustrated by this first report of the prenatal diagnosis of Treacher Collins syndrome using molecular methods.

\section{Patients and methods}

PATIENTS

The relevant part of the family pedigree is shown in fig 1. The pregnancy at risk is indicated as II $\cdot 3$. The father $(\mathrm{I} \cdot 2)$ and half sister (II $\cdot 1)$ are relatively mildly affected with moderate maxillary and mandibular hypoplasia, lower eyelid colobomata, small ears, and narrow external auditory meati. The mother's previous pregnancy resulted in the premature delivery of a severely affected male infant (II $\cdot 2)$, who died at the age of 4 weeks. This child had severe micrognathia with a small mouth and cleft palate, these being factors which contributed to severe respiratory problems to which 


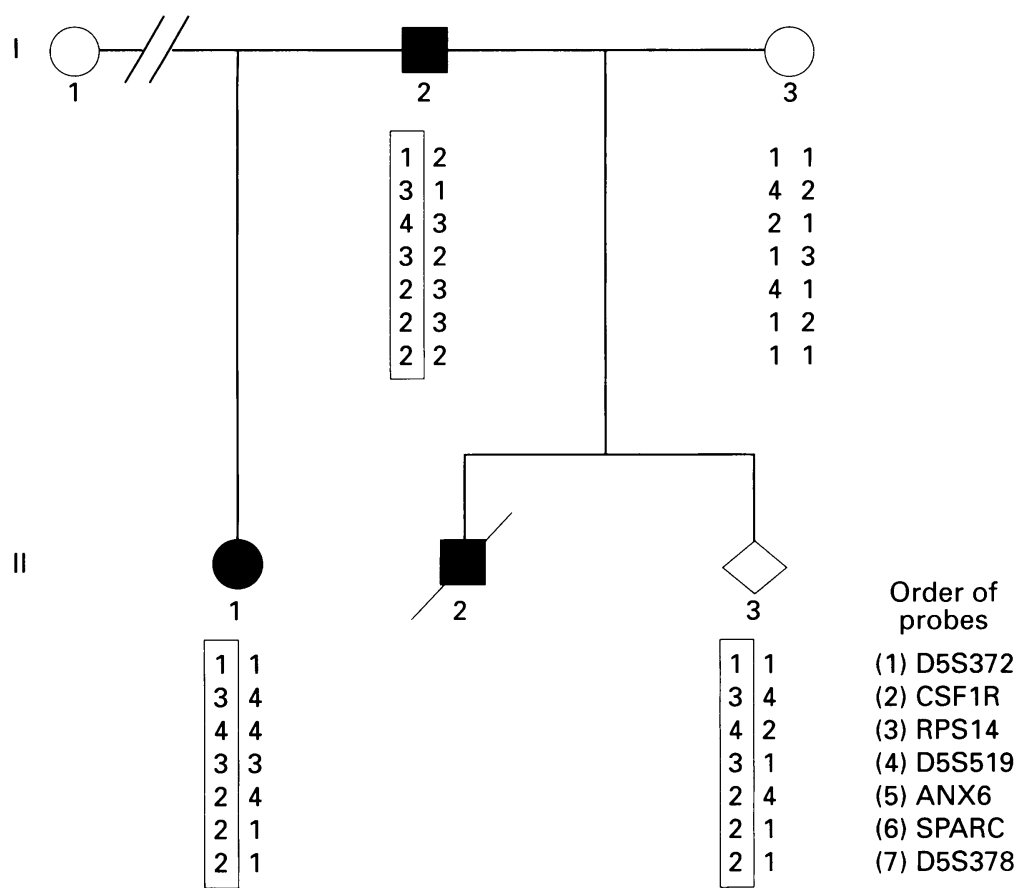

Figure 1 The family pedigree. The STRP haplotype linked to the disease is indicated on the left and is boxed.

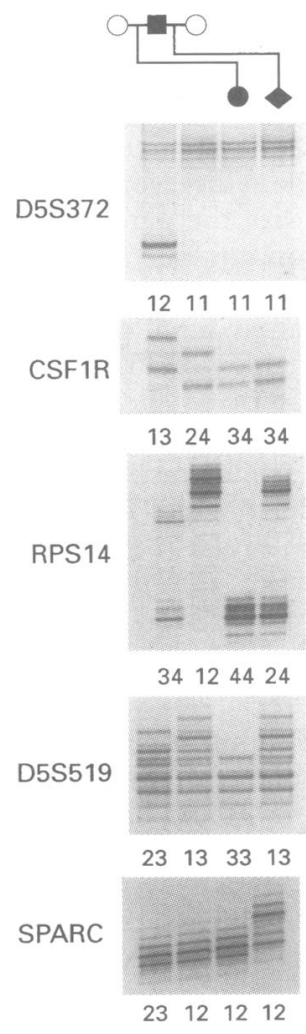

Figure 2 Results of five of the seven STRPs typed in the family. The genotypes are indicated below each STRP. he eventually succumbed. Venous blood samples were taken from the family members with informed consent.

\section{DNA ANALYSIS}

Genomic DNA was extracted from peripheral blood leucocytes or chorionic villus samples using standard procedures and PCR amplified in $5 \mu \mathrm{l}$ reaction volumes containing $4 \mathrm{ng}$ genomic DNA; $10 \mathrm{pmol}$ of each primer, $200 \mu \mathrm{mol} /$ 1 each of dCTP, dGTP, dTTP, and $25 \mu \mathrm{mol} / 1$ of dATP (Pharmacia); $2 \mu \mathrm{Ci}^{35} \mathrm{~S}$-dATP at 500

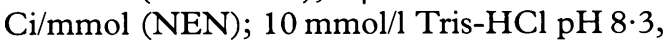
$50 \mathrm{mmol} / 1 \mathrm{KCl}, 1 \mathrm{mmol} / 1 \mathrm{MgCl}_{2}$, and $0.01 \%$ gelatin. The samples were overlaid with mineral oil, heated to $96^{\circ} \mathrm{C}$ for 10 minutes, and cooled to $55^{\circ} \mathrm{C}$. After addition of $0.15 \mathrm{U}$ Taq DNA polymerase, the samples were processed through 35 amplification cycles of $92^{\circ} \mathrm{C}$ for 30 seconds, primer annealing temperature (table) for 30 seconds, $72^{\circ} \mathrm{C}$ for 30 seconds using a Hybaid thermal cycler. The final extension step was lengthened to 10 minutes. Negative controls were established for all reactions. The amplified products were extracted once with chloroform, $2 \mu \mathrm{l}$ was mixed with an equal volume of formamide loading buffer, heated to $80^{\circ} \mathrm{C}$, and the alleles resolved on a $6 \%$ denaturing polyacrylamide gel. The gels were

Short tandem repeat polymorphisms used in the current study

\begin{tabular}{lllc}
\hline Probe & Locus & Heterozygosity & Reference \\
\hline N5.61 & D5S372 & $0 \cdot 75$ & 9 \\
CSF1R & CSF1R & $0 \cdot 86$ & 21 \\
RPS14 & RPS14 & $0 \cdot 66$ & 9 \\
IG90-3 & D5S519 & $0 \cdot 82$ & 6 \\
p68 & ANX6 & $0 \cdot 72$ & 22 \\
SPARC & SPARC & $0 \cdot 80$ & 6 \\
2G10 & D5S378 & $0 \cdot 75$ & 23 \\
\hline
\end{tabular}

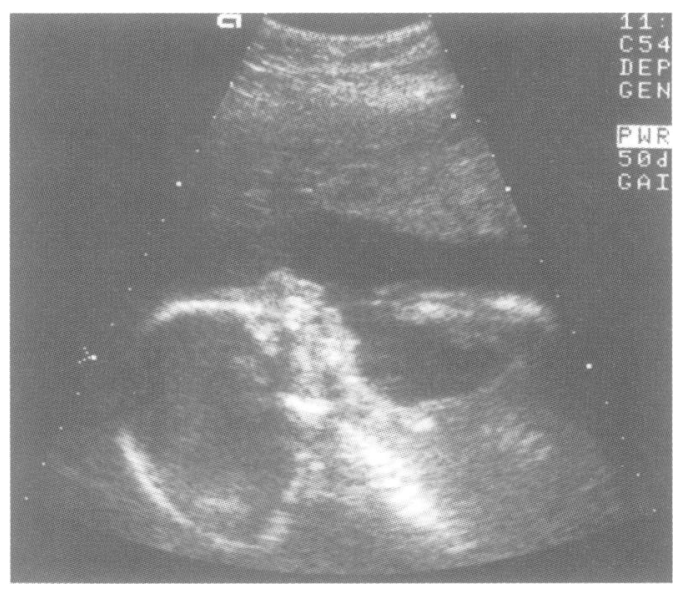

Figure 3 Ultrasound profile of the fetus at 20 weeks' gestation showing marked micrognathia.

fixed, dried, and exposed to Kodak X-Omat film for 24 to 72 hours. Negative controls were established for all reactions.

\section{ULTRASOUND IMAGING}

Ultrasound examination of the pregnancy was performed using an Acuson $128 \mathrm{XP} / 10$ ultrasound machine with a variable frequency vector probe. A routine scan performed at 11 weeks' gestation, before chorionic villus sampling, confirmed dates and a full, detailed assessment was performed at 20 weeks' gestation. Particular attention was paid to the profile of the fetal face and liquor volume.

\section{Results}

The results of the DNA analysis are shown in figs 1 and 2. A total of seven STRPs, which have previously been shown to be closely linked to the TCOF1 locus, were analysed in the family. Analysis of the pedigree showed no evidence of non-paternity. The markers encompass approximately $11 \mathrm{cM}$ on the sex averaged genetic map $^{9}$; two of the markers lie proximal to TCOF1 and the remainder are distal. All but one of the markers was informative in the critical meiosis with no evidence for recombination within the family. The fetus was shown to have inherited the same haplotype from its father as its affected half sister (II $\cdot 1$ ) indicating that there was a very high probability ( $>95 \%$ ) that it had also inherited the TCOF1 gene. However, it was not possible to predict how severely affected the fetus was likely to be.

This information was conveyed to the parents at 12 weeks' gestation. After lengthy discussion and consideration they opted to continue the pregnancy. Detailed ultrasound examination was undertaken at 20 weeks. This indicated the presence of polyhydramnios with no visible stomach bubble. Views of the fetal profile showed marked micrognathia and maxillary hypoplasia (fig 3). Despite these ominous findings the parents felt that, at this late stage, they could not terminate the pregnancy. Subsequent ultrasound scans showed persisting 


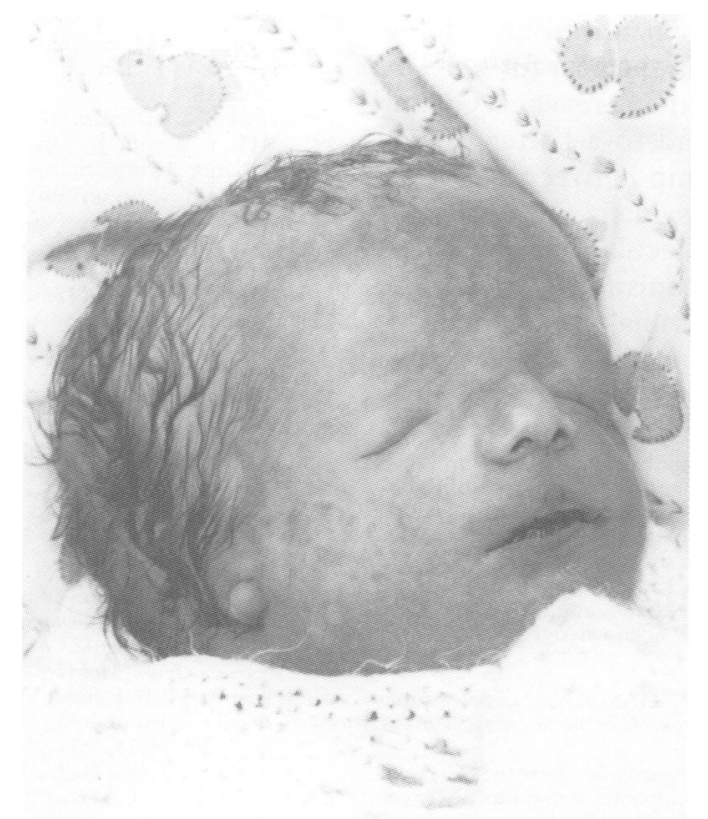

Figure 4 The baby in the immediately postnatal period. She shows severe features of Treacher Collins syndrome including mandibular and zygomatic hypoplasia, downward slanting palpebral fissures, and severe anomalies of the external ears. (Photograph published with parental consent.)

polyhydramnios, with a stomach bubble not appearing until 30 weeks' gestation.

Spontaneous onset of labour occurred at 36 weeks' gestation when the baby, a female given the name Emily, was delivered by caesarean section with birth weight $2510 \mathrm{~g}$. The infant was in good condition at birth but showed obvious severe features of Treacher Collins syndrome (fig 4). Despite the presence of experienced paediatric and anaesthetic staff, the baby could not be intubated and could not maintain her own airway. Death was confirmed at the age of 30 minutes.

\section{Discussion}

In the current investigation, seven STRPs have been used to make first trimester prenatal diagnostic predictions in a family with a history of Treacher Collins syndrome. The highly informative nature of STRPs ${ }^{15}$ makes them excellent markers for use in prenatal diagnosis, where it is important to maximise the amount of linkage information that can be extracted from the family under investigation, particularly where the pedigree structure is not ideal. This was the case in the current study where all but one of the markers was informative in the critical meiosis, despite the fact that the father had remarried and his first wife was not available for investigation. The fact that STRPs are formatted for use with the PCR is also important given that only a limited amount of CVS may be available for analysis. Moreover, application of the PCR to type polymorphic markers is faster than standard blot- ting and hybridisation. In addition, the ability to use this technique to amplify several different markers simultaneously means that it is possible to type a large number of markers in a relatively short time. Nevertheless, STRPs have been shown to exhibit a relatively high mutation rate, particularly in DNA samples extracted from transformed lymphoblastoid cell lines. ${ }^{16}$ However, this is unlikely to present a problem where multiple markers are used to analyse DNA freshly extracted from either blood or a CVS.

Ideally, diagnostic predictions of the type undertaken in the present study should only be performed in families showing significant evidence of linkage to markers in the region of 5q31.3-32 or when the possibility of heterogeneity has been further minimised by the study of additional families. In this regard TCOF1 has been associated with a number of different chromosomal anomalies: two apparently balanced translocations, $t(6 ; 16)(\mathrm{p} 21.31 ; \mathrm{p} 13.11)^{3}$ and $t(5 ; 13)(q 11 ; p 11),{ }^{17}$ and two interstitial deletions, $\operatorname{del}(4)(\mathrm{p} 15.32 \mathrm{p} 14)^{18}$ and $\operatorname{del}(3)$ $(\mathrm{p} 23 \mathrm{p} 24.12)^{19}$ which raise the possibility that the disorder may be heterogeneous. However, in each of these cases, linkage analysis with a series of familial cases of well documented TCOF 1 families failed to show cosegregation with markers for the relevant region. Moreover, the chromosome 6 translocation did not ultimately completely cosegregate with the disease phenotype, ${ }^{3}$ while in the remaining cases the facial gestalt of the patients did not entirely conform to the TCOF1 clinical criteria. Furthermore, while genetic heterogeneity in TCOF1 can not be excluded, all of the 50 families that have been analysed to date support linkage of the disease locus to the region encompassed by the markers used in the current study with none showing unequivocal evidence of non-linkage. ${ }^{7-10}$

These parents specifically requested prenatal diagnosis because of their previous experience of losing a severely affected child in the perinatal period. They had been fully informed about the risks and limitations of a first trimester prenatal diagnosis and were aware that this would not indicate the extent to which a baby with the "high risk" haplotype would be affected. When informed of the CVS results, they decided, quite understandably, to defer a decision in the hope that subsequent detailed ultrasound scanning would show a relatively normal facial profile. Although this proved not to be so, the parents made the agonising decision to continue the pregnancy in what proved to be a forlorn hope that the baby's respiratory problems would not be overwhelming.

This unhappy experience illustrates the dilemma faced by all parents who embark upon prenatal diagnosis in a much wanted pregnancy. It is not surprising that attitudes to termination can alter as the pregnancy proceeds, despite accumulating evidence for a potentially unhappy outcome. To insist on a predetermined course of action given an adverse result would be totally contradictory to the principle of patient autonomy. It would be ideal if noninvasive ultrasound scanning could provide an early prediction of disease severity, but despite 
continuing improvement in ultrasound definition, this is unlikely within the near future. The recent identification of the Treacher Collins syndrome gene ${ }^{20}$ may lead to a better understanding of the relationship between genotype and phenotype, but it is likely to be a considerable time before molecular analysis sheds light on the elusive mechanism underlying the well documented intrafamilial variation in severity which is seen in many families with a history of Treacher Collins syndrome.

We should like to thank the family concerned for their permission to publish the results of this study, and the photograph of Emily, and all of the Treacher Collins syndrome families without whose help the study would not have been possible. The financial support of the Wellcome Trust (grant numbers 036797/Z/92/Z and $044684 / \mathrm{Z} / 95 / \mathrm{Z}$ ), the Hearing Research Trust (grant numbers 073:MAN:MD and 150:MAN:MD), and the Independen Order of Odd Fellows is gratefully acknowledged.

1 Phelps PD, Poswillo D, Lloyd GAS. The ear deformities in mandibulofacial dysostosis. Clin Otolaryngol 1981;6: 15-28.

2 Dixon MJ, Marres HAM, Edwards SJ, Dixon J, Cremers CWRJ. Treacher Collins syndrome: correlation between clinical and genetic linkage studies. Clin Dysmorphol 1994; 3:96-103.

3 Dixon MJ, Haan E, Baker E, et al. Association of Treacher Collins syndrome and translocation $6 \mathrm{p} 21.31 / 16 \mathrm{p} 13.11$ : Collins syndrome and translocation $6 \mathrm{p} 21.31 / 16 \mathrm{p} 13.11$ : exclusion of the locus from these

4 Dixon MJ, Read AP, Donnai D, Colley A, Dixon J, Williamson $\mathrm{R}$. The gene for Treacher Collins syndrome maps to the long arm of chromosome 5. Am f Hum Genet 1991 49:17-22

5 Dixon MJ, Dixon J, Raskova D, et al. Genetic and physical mapping of the Treacher Collins syndrome locus. Refinement of the localization to chromosome 5q32-33.2. Hum Mol Genet 1992;1:249-53.

6 Dixon MJ, Dixon J, Houseal T, et al. Narrowing the position of the Treacher Collins syndrome locus to a small interval between three new microsatellite markers at 5q32-33.1. Am f Hum Genet 1993;52:907-14.

7 Jabs EW, Li X, Coss CA, Taylor EW, Meyers DA, Weber JL. Mapping the Treacher Collins syndrome locus to 5q31.3-q33.3. Genomics 1991;11:193-8.
8 Jabs EW, Li X, Lovett M, et al. Genetic and physical mapping of the Treacher Collins syndrome locus with mapping of the Treacher Collins syndrome locus with respect to loci

9 Loftus SK, Edwards SJ, Scherpbier-Heddema T, Buetow $\mathrm{KH}$, Wasmuth JJ, Dixon MJ. A combined genetic and radiation hybrid map surrounding the Treacher Collins syndrome locus on chromosome 5q. Hum Mol Genet 1993; 2:1785-92.

10 Edery P, Manach Y, Le Merrer M, et al. Apparent genetic homogeneity of the Treacher Collins-Franceshetti syndrome. Am 7 Med Genet 1994;52:174-7.

11 Nicolaides KH, Johansson D, Donnai D, Rodeck CH. Prenatal diagnosis of mandibulofacial dysostosis. Prenat Diagn 1984;4:201-5.

12 Meizner I, Carmi R, Katz M. Prenatal ultrasonic diagnosis of mandibulofacial dysostosis (Treacher Collins syndrome). $₹$ Clin Ultrasound 1991;19:124-7.

13 Milligan DA, Harlass FE, Duff P, Kopelman JN. Recurrence of Treacher Collins syndrome with sonographic findings. Mil Med 1994;159:250-2.

14 Rodeck $\mathrm{CH}$, Nicolaides $\mathrm{KH}$. Fetoscopy and fetal tissue sampling. Br Med Bull 1983;39:332-7.

15 Weber JL. Informativeness of human (dC-dA)n.(dG.dT)n polymorphisms. Genomics 1990;7:524-30.

16 Weber JL, Wong C. Mutation of human short tandem repeats. Hum Mol Genet 1993;2:1123-8.

17 Balestrazzi P, Baeteman MA, Mattei MG, Mattei JF. Franceshetti syndrome in a child with a de novo balanced translocation $(5 ; 13)(\mathrm{q} 11 ; \mathrm{p} 11)$ and significant decrease of hexosaminidase B. Hum Genet 1983;64:305-8.

18 Jabs EW, Coss CA, Hayflick SJ, et al. Chromosomal deletion $4 \mathrm{p} 15.32-\mathrm{p} 14$ in a Treacher Collins syndrome patient: exclusion of the disease locus from and mapping of an-
onymous DNA sequences to this region. Genomics 1991; onymous DNA

19 Arn PH, Mankinen C, Jabs EW. Mild mandibulofacial dysostosis in a child with a deletion of $3 \mathrm{p} . A m \mathcal{F} \mathrm{Med}$ Genet 1993;46:534-6.

20 The Treacher Collins Syndrome Collaborative Group. Positional cloning of a gene involved in the pathogenesis of Treacher Collins syndrome. Nature Genet 1996;12:130-6.

21 Polymeropoulos MH, Xiao H, Rath DS, Merril CR. Dinucleotide repeat polymorphism at the human c-fms nucleotide repeat polymorphism at the human c-fms
protooncogene for the CFS-1 receptor (CFS1R). Nucleic protooncogene for the CFS

22 Loftus SK, Dixon J, Koprivnikar K, Dixon MJ, Wasmuth JJ. Transcriptional map of the Treacher Collins candidate gene region. Genome Res 1996;6:26-34.

23 Ryan SG, Dixon MJ, Nigro MA, et al. Genetic and radiation hybrid mapping of the hyperekplexia region on chromosome 5q. Am f Hum Genet 1992;51:1334-43. 